\title{
Fertilized to death
}

\section{Vast quantities of nitrogen being poured onto farmers' fields are wreaking havoc with our forests. Nicola Nosengo investigates.}

otted throughout forests around the world, yellowed leaves and thinning crowns suggest that some trees are dying an early death. But the culprit may come as something of a surprise. It isn't just pollution spewed from car fumes, or damage from insects proliferating thanks to global warming. Our forests are facing a quieter villain. They're being plagued by the very stuff that has provided people with food for the past hundred years - fertilizer.

The use of fertilizer changed dramatically in the twentieth century. In the late 1890s, people struggled to get enough fertilizer for their fields - the main sources were bird guano from the Pacific islands and saltpetre from the deserts of Chile. But as the world's population grew, it became clear that we would need a cheaper, easier way to get a usable form of nitrogen. That problem was solved in 1909 by Fritz Haber and Carl Bosch, who devised the first industrial process to turn nitrogen gas $\left(\mathrm{N}_{2}\right)$ in the air into ammonia $\left(\mathrm{NH}_{3}\right)$. The result was a ready supply of cheap fertilizer, which has powered global food production ever since ${ }^{1}$.

But that success story is now becoming an environmental scourge. Unused fertilizer is washing off fields into rivers, poisoning coastal waters and causing acid rain. Scientists are worried that this flood of food could be causing the slow - and possibly irreversible — death of our forests.

Nitrogen is a relatively unreactive gas. But it can spawn a range of reactive molecules thanks to the work of certain bacteria, the burning of fossil fuel or the manufacture of fertilizer. Collectively known as reactive nitrogen, this family of molecules includes ammonia, nitrate ions $\left(\mathrm{NO}_{3}{ }^{-}\right)$and nitrogen oxide gases $\left(\mathrm{NO}_{x}\right)$, and its production has more than doubled over the past century.

\section{Food for thought}

Until the early 1900s, most reactive nitrogen was produced by bacteria and amounted to about 100 million tonnes per year. But human activity alone now generates more than 160 million tonnes per year (ref. 2) 25 million tonnes through burning fossil fuels, mostly in cars, and more than 100 million tonnes from the industrial production of fertilizer. If the current rate of increase continues, global production of reactive nitrogen is predicted to reach between 250 million and 900 million tonnes per year by 2100 .

The trouble is that a lot of this nitrogen doesn't end up where it is meant to be - in our food. James Galloway, an environmental
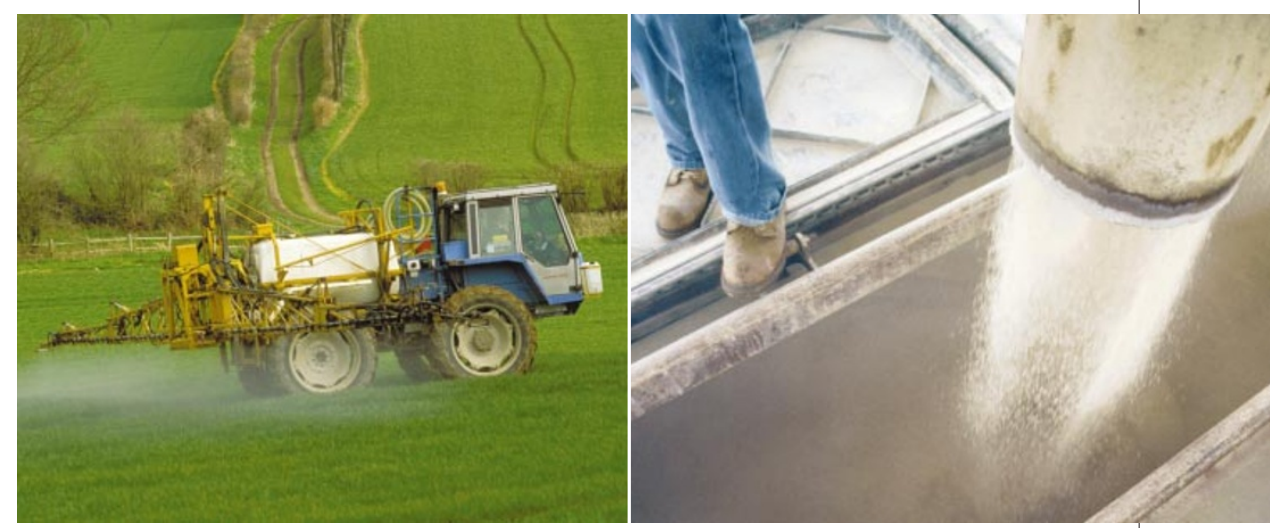

scientist at the University of Virginia in Charlottesville, estimates that almost half of the nitrogen spread onto fields is not taken up by crops but instead washes away.

Most of it leaks through the soil into groundwater as nitrate, which then washes into ponds or coastal waters. There the excess nutrient fuels the rampant growth of algae, which in turn uses much of the oxygen in the water, suffocating fish and other marine life. The agricultural runoff down the Mississippi river is so packed with nitrogen and other nutrients that there is now a giant patch of algae covering 20,000 square kilometres in the Gulf of Mexico. Throughout the United States, one-third of the coastal rivers and bays show similar effects on a smaller scale ${ }^{2}$.

Less commonly, excess nitrate can end up in drinking water, where it can cause 'blue baby' syndrome, or methaemoglobinaemia. In this rare but sometimes fatal condition, red blood cells are no longer able to perform their vital role of carrying oxygen around the body, which subsequently turns an infant's lips an oxygen-deprived blue.

Such effects on coastal and human health have grabbed the headlines and public attention, but scientists are now concerned about more subtle events. A significant amount of reactive nitrogen ends up in the air as ammonia and $\mathrm{NO}_{x}$ where it increases the amount of low-level ozone, which in turn contributes to smog and global warming. In the atmosphere, some $\mathrm{NO}_{x}$ dissolves in water vapour to produce nitric acid, which falls back to the ground as acid rain. The ammonia, although it is alkaline, can also make soils more acidic - as microbes digest the ammonia they produce nitrate and acidic hydrogen ions.

Much of this reactive nitrogen is falling on our forests, where the results can already been seen ${ }^{3}$. Trees are dying and the relative abundance of different plant species in some woods has started to change 4 . "The effect on forests is slower and less visible than on coastal environments," says Galloway. But that could mean that once effects become obvious, it may be too late for the trees to recover.

In the late 1980s, John Aber of the University of New Hampshire in Durham described how a forest might react to a nitrogen overdose $^{5}$. He suggested that a forest doused with nitrogen initially thrives, but at some point, input of nitrogen exceeds demand. As plants are no longer able to absorb it, the nitrogen builds up in the soil, mostly as nitrates. These negatively charged ions attract positively charged ions such as calcium and magnesium, and carry them into the water table. This deprives the trees of fundamental nutrients just as their demand for them is growing. Weakened, the trees become increasingly vulnerable to frost, drought and parasites. At the same time, rising soil acidity causes a loss in biodiversity in the undergrowth.

\section{Poisoned land}

Confirming Aber's hypothesis and predicting the likely course of future events is a tricky proposition. To that end, researchers at the IVL Swedish Environmental Research Institute in Gothenburg have been studying nitrogen saturation in the Gårdsjön forest in southeastern Sweden since 1991. Part of the forest is covered with a transparent roof, watered with clean water and acts as a control site. In another section, researchers have been adding $40 \mathrm{~kg}$ of nitrogen per hectare per year to a site that used to get less than 10 $\mathrm{kg}$ per hectare from atmospheric depositions - an unpolluted forest should get less than 5 $\mathrm{kg}$ per hectare per year. The massive overdose speeds up the process of nitrogen poisoning, giving scientists an idea of what might occur in the future. "Not very much happened for the first five years," says Filip Moldan of the Swedish Environmental Research Institute, who coordinates the project. "But since then 


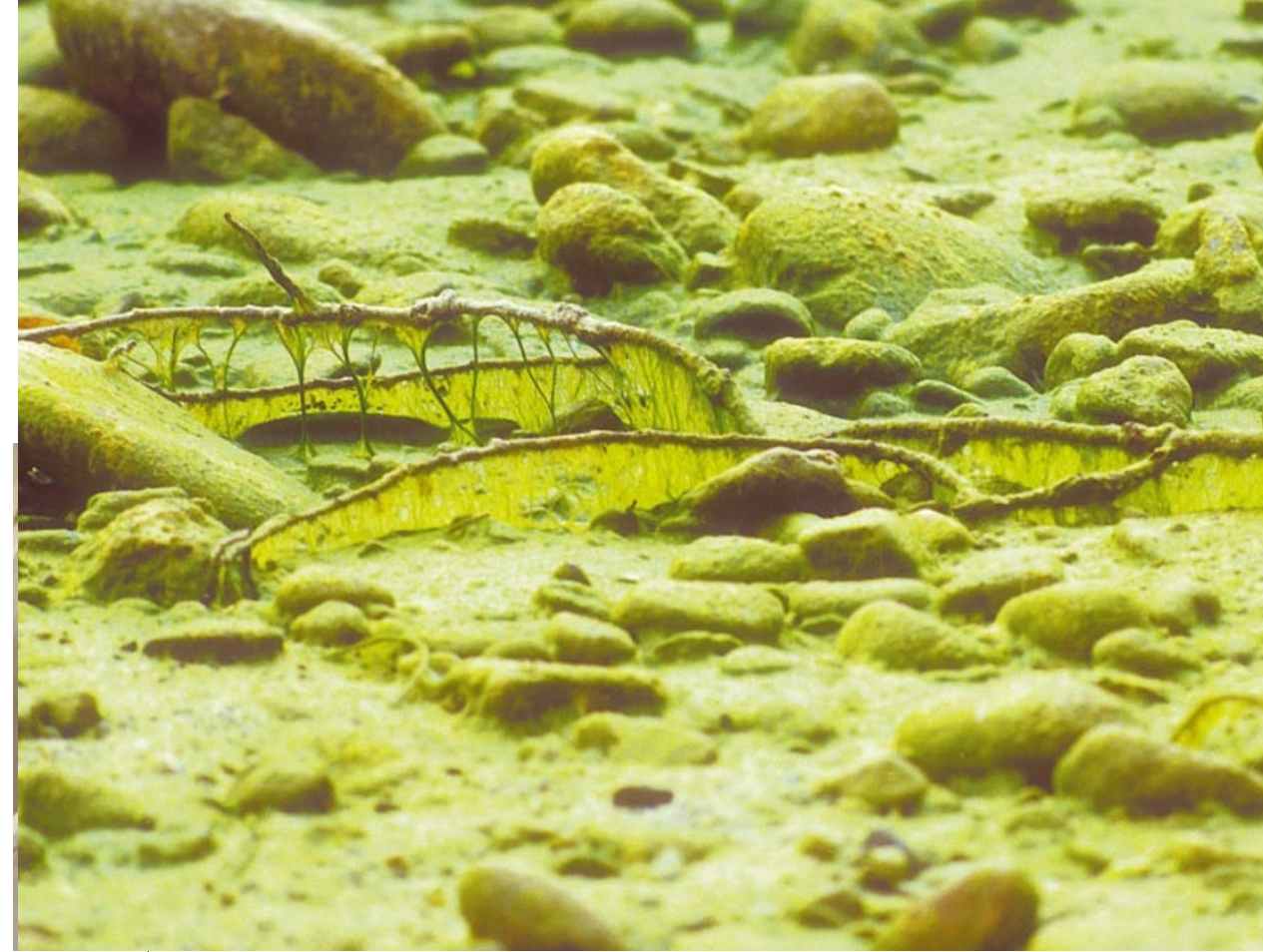

we are seeing changes wherever we look."

The over-fertilized trees are now growing faster than normal, and the levels of various nutrients in the foliage have changed - as predicted by Aber, the leaves contain more nitrogen, and less calcium and magnesium than in normal trees. And about $10 \%$ of the added nitrogen is now leaking out of the forest as nitrate in groundwater, says Moldan. He hopes to keep the experiment running for another decade to see how the saturation process will proceed. "At some point the soil will probably become unable to retain any of the nitrogen added, and the forest will start to decline," he predicts. "But we don't know how long this will take."

Nor is it clear how different types of forests will respond. Although there isn't much information to go on, studies suggest that humid tropical forests will reach nitrogen saturation more quickly than those in temperate climes ${ }^{6}$. Some tree species, such as sugar maple and red spruce, seem to be particularly sensitive to additional nitrogen and could disappear completely from some sites.

So how can we save our forests? Many European countries have tried to counteract the build-up of reactive nitrogen by liming adding calcium or magnesium carbonates to the soil. That reduces the soil's acidity and adds back nutrients. But the process is too expensive to use on a large scale. And overliming would kill soil microbes, again altering the ecosystem. "Liming only cures the symptoms, not the disease," says Aber.

A few tentative steps were taken to address the problem some 30 years ago. In the 1970s, both sulphur and nitrogen were flagged up as the source of acid rain. Initiatives - such as a variety of national laws including the 1970 Clean Air Act in the United States - tried to limit both sulphur oxides and $\mathrm{NO}_{x}$. But the $\mathrm{NO}_{x}$ provisions only controlled the amount produced by individual cars, largely ignoring agricultural contributions. Only the sulphur controls were truly successful. "Sulphur deposition to soil in Europe and North America has decreased up to $70 \%$, but nitrogen deposition is constant or slightly increasing," says Aber.

\section{Cutting back}

More recently, 28 European countries signed the 1999 Gothenburg protocol, one of the goals of which is to reduce emissions of $\mathrm{NO}_{x}$ by $41 \%$ and ammonia by $17 \%$ by 2010 , compared with emissions in 1990. As of 2002 they seemed to be on track: emissions of $\mathrm{NO}_{x}$ and ammonia were down $23 \%$ and $6 \%$, respectively. But that is mainly thanks to controls on fossil-fuel burning in Germany, Britain and the Netherlands, which won't be able to reduce emissions much further, says Moldan. Meanwhile emissions from some

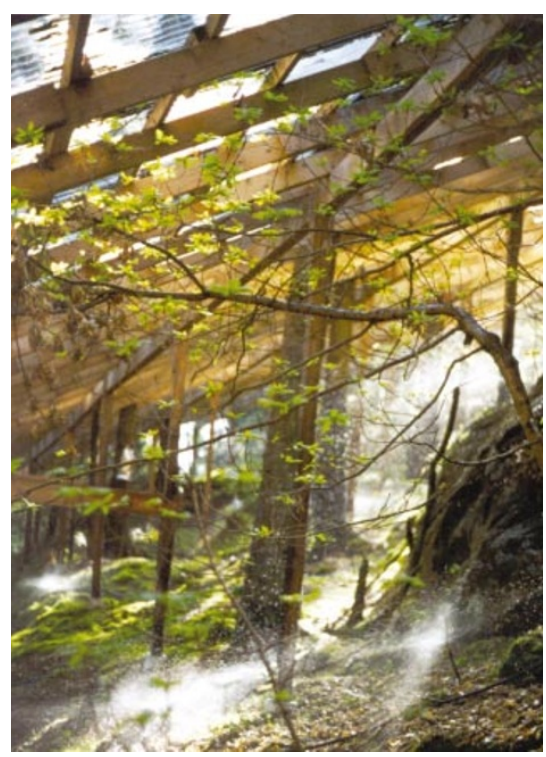

A plastic canopy protects trees in Gårdsjön, as part of an experiment to test the effects of nitrogen.
Mixed blessing: the face of farming has been transformed by the industrial production of nitrogen-based fertilizer, shown here being spread on a field (opposite, far left) and loaded into a rail car. But overuse has led to suffocating algal blooms in rivers (left) and damage to ecosystems caused by acid rain (below).

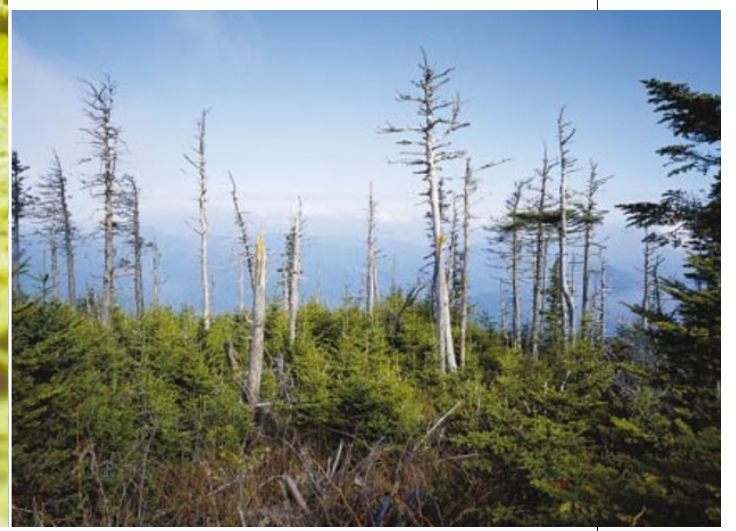

countries in Europe, as well as China and Russia, are rapidly increasing.

Scientists are sceptical about how effective the protocol will prove to be, particularly as it fails to address how agriculture can reduce nitrogen emissions in the face of a growing population and its need for food. "Countries such as China have no intention of reducing their use of nitrogen," says Moldan. "In fact they are firmly committed to increasing it."

Concerned scientists will meet next October in Nanjing, China, at the 3rd International Nitrogen Conference. Their aim is to propose a 'Nanjing protocol' to address the issue of nitrogen at a global level. According to Galloway, one of the meeting's promoters, the protocol should include not only limitations on $\mathrm{NO}_{x}$ and ammonia emissions, but should focus on an integrated approach to managing reactive nitrogen.

The point, he says, is to make nitrogen use in farming more efficient. Nitrogen can be recycled from crop waste, manure and slaughtered animals, either by turning it back into gaseous $\mathrm{N}_{2}$ or into animal feed ${ }^{7}$. Farmers could also use less fertilizer, if there were ways to cut usage without reducing cropyields. All of these ideas are technically feasible, says Galloway, but are so expensive that no one currently bothers. That needs to change. "We cannot replace reactive nitrogen as we did with chlorofluorocarbons in refrigerators," says Galloway."We need it and we will need it more in the future, there is no way around that." Nicola Nosengo was, until recently, an intern in Nature's Munich office.

1. Smil, V. Nature 400, 415 (1999).

2. Galloway, J. N. et al. BioScience 53, 341-356 (2003).

3. Aber, J. et al. BioScience 48, 921-934 (1998).

4. De Vries, W. et al. in Empirical Critical Loads for Nitrogen, Proc. Expert Workshop, Bern, Switzerland, 11-13 November (eds

Achermann, B. \& Bobbink, R.) 199-207 (SAEFL, Bern, 2003) Aber, J. D., Nadelhoffer, K. J., Steudler, P. \& Melillo, J. M. BioScience 39, 378-386 (1989).

Matson, P., Lohse, K. A. \& Hall, S. J. Ambio 31, 113-119 (2002).

Cowling, E. B. \& Galloway, J. N. J. Anim. Sci. 80, (suppl. 2) E157-E167 (2002). 